\title{
UNA CLASIFICACIÓN DE LAS MODALIDADES DE VULNERACIÓN DEL DERECHO A LA VIDA EN COLOMBIA
}

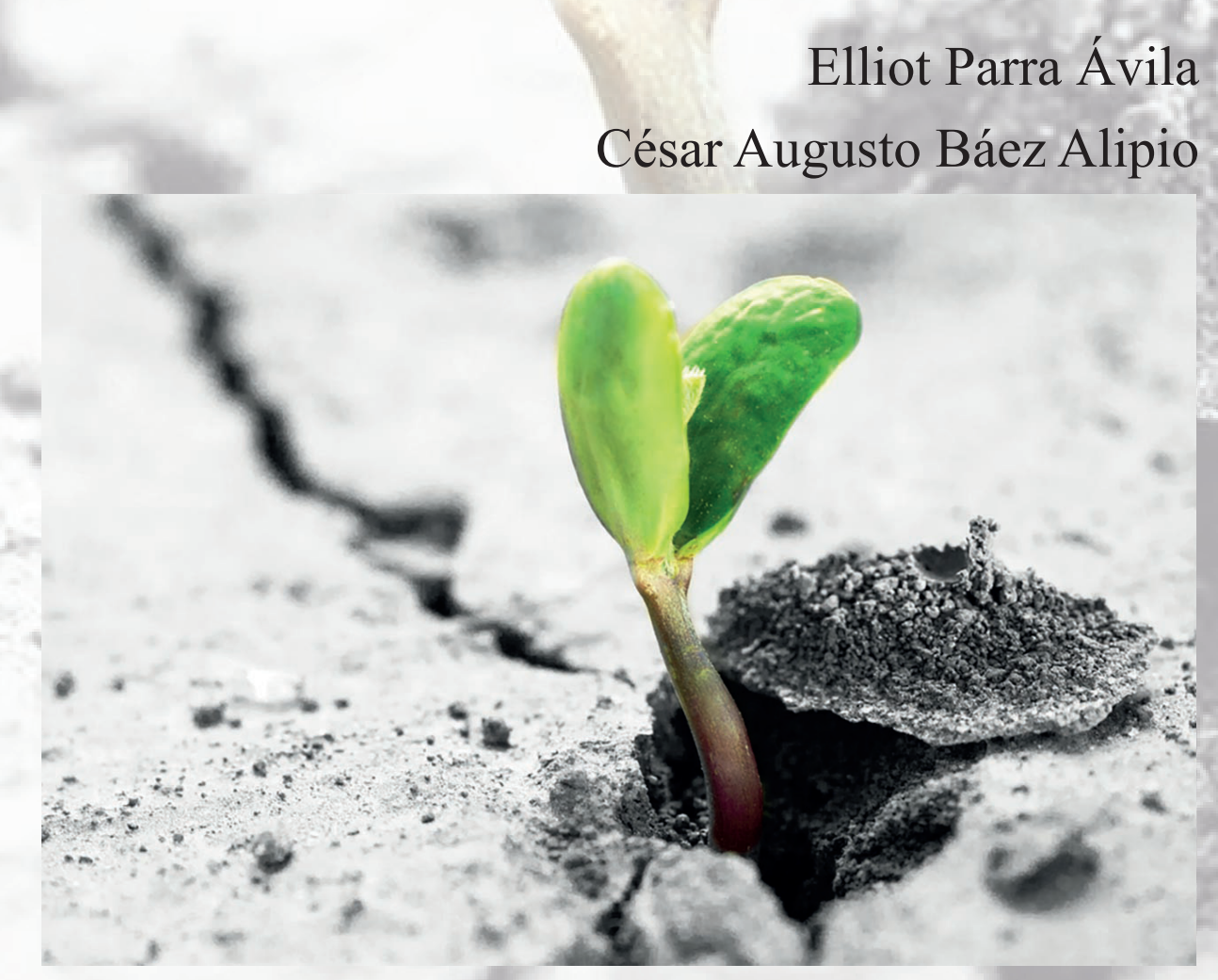





\title{
UNA CLASIFICACIÓN DE LAS MODALIDADES DE VULNERACIÓN DEL DERECHO A LA VIDA EN COLOMBIA*
}

\author{
Elliot Parra Ávila \\ César Augusto Báez Alitio \\ Universidad Militar Nueva Granada
}

\section{Resumen}

La complejidad conceptual empleada por las ciencias del derecho y la medicina dificulta la tarea de estudiar los diversos matices del derecho a la vida y sus formas de vulneración. En el presente artículo se describen las diferencias conceptuales entre las modalidades de vulneración del derecho a la vida en Colombia, para clasificarlas, identificar su regulación jurídica y exponer sus problemas terminológicos, de forma que puedan ser abordadas por el mayor espectro posible de disciplinas. La metodología empleada se basa en la filosofía del lenguaje y lleva una secuencia de la definición médica y la definición jurídica del término, la caracterización de los sujetos involucrados en las nociones y la ubicación del concepto en una taxonomía fundamentada en la voluntariedad de la vulneración. Para ello se expondrán y organizarán las facetas del término vida y luego las del término vulneración de la vida. A manera de conclusión, gracias a la simplificación conceptual, se puede afirmar con seguridad que el derecho a la vida es jurídicamente disponible en varias circunstancias.

Palabras clave: derecho a la vida, modalidades de vulneración, disponibilidad de derechos.

Los autores: Elliot Parra Ávila, magíster en Derecho y master of Research. Docente asociado de la Facultad de Derecho de la Universidad Militar Nueva Granada e investigador del grupo de investigación en derecho público. Correo electrónico: elliot.parra@unimilitar.edu.co

César Augusto Báez Alipio, abogado. Miembro del semillero de investigación Octava Papeleta. u0303844@unimilitar.edu.co

Recibido: 17 de marzo de 2018; evaluado: 5 de julio de 2018; aceptado: 21 de agosto de 2018.

* Artículo de reflexión producto del Proyecto DER-2059, financiado por la Universidad Militar Nueva Granada, entre el 24 de febrero de 2016 y el 23 de febrero de 2017. 


\title{
A CLASSIFICATION OF THE VULNERATION MODALITIES OF THE RIGHT TO LIFE IN COLOMBIA
}

\author{
Elliot Parra Ávila \\ César Augusto Báez Allipio \\ Universidad Militar Nueva Granada
}

\begin{abstract}
The conceptual complexity employed by law and medical sciences makes it difficult to study the different nuances of the right to life and forms of its violation. The present article seeks to describe conceptual differences between forms of violation of the right to life in Colombia, aiming to classify them, identify their legal regulation, and expose their terminological problems, in such a way that they can be addressed by the greatest possible spectrum of disciplines. The methodology used is based on the philosophy of language and has the following sequence: medical definition of the term, legal definition of the term, characterization of the subjects involved in these definitions, and location of the term in a taxonomy based on the willfulness of violation. For this purpose, the paper explains and organizes different facets of the term "life," followed by different facets of the term "violation of life," according to the proposed methodology. As a conclusion, thanks to conceptual simplification, it can be safely asserted that the right to life is legally disposable in various circumstances.
\end{abstract}

Keywords: right to life, forms of violation, disposability of rights.

About the authors: Elliot Parra Ávila, MA in Law and MA in Research. Associate Professor at the Faculty of Law of the Universidad Militar Nueva Granada and researcher of the research group in public law. Email: elliot.parra@unimilitar.edu.co

César Augusto Báez Alipio, lawyer. Member of the Research Incubator "Octava Papeleta." Email: u0303844@unimilitar.edu.co

Received: March 17, 2018; reviewed: July 5, 2018; accepted: August 21, 2018 


\section{Introducción}

La Constitución Política de Colombia refiere que: "Colombia es un Estado Social de Derecho [...] fundado en el respeto de la dignidad humana [... [.". ${ }^{1}$ De lo anterior es posible inferir que uno de sus pilares corresponde a la protección de la vida, derecho de cuya efectividad dependen las demás garantías consagradas en la Carta. La actual Constitución se refiere a él en términos de "protección a la vida y calidad de vida”, entre otras configuraciones jurídicas que le otorgan una especial protección. ${ }^{2}$

No obstante, surge una cuestión de relevancia jurídica: ¿El derecho a la vida en Colombia otorga la facultad jurídica para terminar con la vida propia? No nos referimos a la licitud del suicidio, punto que no tiene relevancia en el derecho colombiano, sino a las dificultades prácticas que implican otras formas de acabar con la vida que requieren actos preparatorios de carácter médico-logístico para consumar la propia muerte, como la eutanasia y el suicidio asistido.

En el contexto de la irrupción del suicidio asistido ${ }^{3}$ en seis países (Bélgica, Canadá, Estados Unidos, ${ }^{4}$ Holanda, Luxemburgo, Suiza) y para responder con más precisión si el suicidio asistido es jurídicamente viable en el ordenamiento colombiano, primero se hace necesario exponer un marco conceptual más amplio acerca de las facetas que pueden adoptar el derecho a la vida y sus modalidades de vulneración.

La pregunta que se pretende responder en este artículo es la siguiente: ¿Cuáles son las diferencias conceptuales entre las modalidades de vulneración del derecho a la vida en Colombia que nos permiten identificar su regulación jurídica? Es posible plantear como hipótesis: El derecho a la vida en Colombia supone una

\footnotetext{
República de Colombia, Constitución Política (Bogotá: Legis, 1991), art. 1.

2 Adicional al Preámbulo, que sostiene: "[...] con el fin de fortalecer la unidad de la Nación y asegurar a sus integrantes la vida [...]", las normas constitucionales que mencionan la vida sin calificación adicional alguna son el Artículo 2: "Las autoridades de la República están instituidas para proteger a todas las personas residentes en Colombia, en su vida [...]"; el Artículo 11: "El derecho a la vida es inviolable. No habrá pena de muerte"; el Artículo 44: "Son derechos fundamentales de los niños: la vida [...]" y el Artículo 95: "Son deberes de la persona y del ciudadano: [... 2. Obrar conforme al principio de solidaridad social, respondiendo con acciones humanitarias ante situaciones que pongan en peligro la vida o la salud de las personas". República de Colombia, Constitución Politica, Preámbulo, arts. 2, 11, 44, 95.

3 También conocido como PAS, por su nombre en inglés: physician-assisted suicide, según la CMA. Canadian Medical Association, "Physician-assisted death", Canadian Medical Association Journal 152, núm. 2 (1995): 248A-248B.

4 Permitido únicamente en los estados de California, Montana, Oregón, Vermont y Washington. Mariana Parreiras et al., "Eutanasia y suicidio asistido en países occidentales: una revisión sistemática", Bioética 24, núm 2 (mayo/agosto 2016).
} 
interpretación amplia y no exegética o limitada, que lleva a inferir que la renuncia a la propia vida es jurídicamente viable, por cuanto el individuo está en capacidad de terminar con ella si así lo desea (disponibilidad), siempre y cuando se encuentre en ciertas circunstancias que posibilitan el procedimiento (relatividad), lo que sin duda alguna conllevará a concluir que en Colombia existe una disponibilidad relativa del derecho a la vida propia por parte de su titular.

\section{Método}

Cuando la Corte Constitucional colombiana despenalizó la eutanasia en 1997, el término "suicidio asistido" no había alcanzado reconocimiento normativo en ningún país del mundo. ${ }^{5}$ No obstante, la propia Corte reconoce:

[...] la eutanasia es tan solo un procedimiento para proteger el derecho a morir dignamente. Existen situaciones e hipótesis en las cuales no será el medio apropiado para garantizar la plena vigencia de los derechos fundamentales. Por ejemplo, algunos países han aprobado el suicidio asistido como alternativa para causar la muerte de un paciente que padezca una enfermedad terminal. ${ }^{6}$

Esa situación presenta al menos un problema de sentido común, que propicia la pregunta sobre la racionalidad de que la eutanasia (practicada por otro) esté despenalizada y regulada, mientras no hay pronunciamiento expreso de la Corte Constitucional sobre el suicidio asistido (practicado por el interesado).

Esa confusión ha alcanzado a la academia y algún texto ya trata los dos términos conjuntamente e incluye a Colombia como sujeto de estudio. ${ }^{7}$

La importancia de la claridad lingüística en el análisis del derecho ha sido planteada por Parra. ${ }^{8}$ En la medida en que el derecho está construido con lenguajes naturales u ordinarios, adolece de los mismos problemas de aquellos. La filosofía del lenguaje ordinario defiende las siguientes tesis o actitudes: a) para tratar los

5 La regulación surge en Oregón en octubre de 1997, en Bélgica y Holanda en 2002, en Luxemburgo en 2009 y en Canadá en 2015. Canadian Medical Association, Euthanasia and Assisted Suicide (Ottawa: AMC/CMA, 2007), 248A.

6 Colombia, Corte Constitucional, Sentencia T-970 de 15 de diciembre de 2014, M. P. Luis Vargas.

7 Parreiras et al., "Eutanasia y suicidio asistido en países occidentales", 356.

8 Elliot Parra Ávila, "Análisis sobre las obligaciones" Pensamiento Jurídico 16, núm. 16 (2006), https://revistas. unal.edu.co/index.php/peju/article/view/40372/pdf_519 (acceso junio 6, 2018). 
problemas filosóficos hay que usar un lenguaje llano, esto es, claro y simple; b) los problemas filosóficos, sin excepción, son pseudoproblemas. Se originan en abusos del lenguaje ordinario; c) la tarea filosófica consiste básicamente en la elucidación de conceptos ordinarios, incorporados al lenguaje común, y d) el lenguaje ordinario recoge las principales distinciones que vale la pena hacer en todos los aspectos prácticos de la vida humana. ${ }^{9}$

La metodología de la filosofía del lenguaje ordinario parte de la premisa de que la identificación exacta del ámbito de uso de los términos y las expresiones facilita la tarea tanto de la filosofía como la del derecho. En el caso del derecho a la vida y sus vulneraciones, tenemos además que interviene con fuerza la ciencia médica y eso aumenta la necesidad de simplificar la terminología, de forma que pueda ser empleada por el mayor espectro posible de disciplinas.

En la medida en que la vida, como todos los derechos, no tiene carácter absoluto y es uno de los derechos que presenta mayor variedad de modalidades de vulneración, la claridad mencionada se hace jurídicamente necesaria. Por ello, la metodología empleada para hacer la clasificación sigue la lógica de los sucesos, ya que primero sucede el fenómeno biológico, luego es regulado y de esa regulación se desprenden consecuencias; por eso, el análisis de cada término consistirá en i) aportar su definición médica, con base en la OMS; ii) aportar su definición jurídica, con base en la Corte Constitucional; iii) caracterizar los sujetos intervinientes en él y la voluntariedad de dicha intervención, y iv) proponer la clasificación que combina los criterios de secuencia lógica y voluntariedad.

\section{Discusión}

La secuencia en la que serán expuestos los términos de la clasificación es la siguiente: vida, vida digna, distanasia, muerte natural, suicidio, eutanasia, suicidio asistido, homicidio por piedad, homicidio, eugenesia y genocidio.

\subsection{La vida y sus facetas}

La Organización Mundial de la Salud (OMS) analiza la vida desde el concepto de "calidad de vida", para lo cual toma en cuenta múltiples factores (físicos, psicológicos,

9 Genaro Carrió, "Introducción" en Cómo hacer cosas con palabras, comp. James Urmson (Buenos Aires: Paidós, 1971). 
sociales y espirituales), sin describir de manera concreta lo que el organismo entiende por "vida" en su expresión médica básica.

En contraste, dado que la más conocida de las definiciones jurídicas de vida es precaria, "[...] La existencia legal de toda persona principia al nacer, esto es, al separarse completamente de su madre [...]", ${ }^{10}$ le ha correspondido a la Corte Constitucional enriquecer el término.

En la Sentencia T-408/13 se encuentra la elaboración más completa del concepto jurídico de vida y retoma la posición sentada en la Sentencia T-395/98, donde se expone que:

[... el el concepto de vida no es un concepto limitado a la idea restrictiva de peligro de muerte, sino que se consolida como un concepto más amplio [... ], extendiéndose al objetivo de garantizar también una existencia en condiciones dignas. Lo que se pretende es respetar la situación "existencial de la vida humana en condiciones de plena dignidad", ya que "al hombre no se le debe una vida cualquiera, sino una vida saludable", en la medida en que sea posible [...] (cursivas propias). ${ }^{11}$

La línea que ha mantenido la Corte Constitucional sobre el derecho a la vida es su protección en condiciones de dignidad humana.

Por otra parte, la doctrina ha considerado que:

i) el preámbulo establece a la vida como uno de los fines del Estado, [...], ii) el artículo 2 define que las autoridades "están instituidas para proteger a todas las personas residentes en Colombia, en su vida"; iii) el artículo 11 consagra que "el derecho a la vida es inviolable" [...] el concepto de vida debe diferenciarse entre la protección de la vida como valor constitucional y su protección como derecho fundamental.

[...]. En este orden de ideas [...] todos los seres humanos son titulares del derecho a la vida [...]. Desde esta perspectiva, si bien corresponde al legislador protegerla [...], esto no implica que estén justificadas todas las medidas que dicte con esa finalidad, "porque a pesar de su relevancia constitucional la vida no tiene el

10 Colombia, Congreso de la República, Ley 57 de 1887, "Por la cual se expide el Código Civil" (Bogotá: Diario Oficial 2867, 31 de mayo de 1873), art. 90.

11 Colombia, Corte Constitucional, Sentencia T-408 de 4 de julio de 2013, M. P. Jorge Pretelt. 
carácter de un valor o de un derecho absoluto y debe ser ponderada con los otros valores, principios y derechos constitucionales" (cursivas propias). ${ }^{12}$

Como se observa en la jurisprudencia y en la doctrina, la vida como derecho no es absoluta y debe ser protegida desde la perspectiva de dignidad humana. Por otra parte, la vida como bien y como derecho (que son miradas diferentes) también está reconocida en numerosas disposiciones internacionales. ${ }^{13}$

La vida es el derecho más importante para los seres humanos, porque es el único por cuya negación se vuelven ineficaces las demás garantías consagradas en la Carta. Además, también es el único derecho imposible de reivindicar una vez se ha vulnerado. A continuación se expone lo que hemos considerado "facetas de la vida en Colombia".

\subsection{Vida digna}

Como se dijo en líneas precedentes, la OMS suele emplear el término "calidad de vida" ${ }^{14}$ sin concretar lo que se entiende por "vida" en su expresión médica básica.

Por su parte, la Constitución de 1991 protege la vida, pero no de cualquier clase, pues propende por una "vida digna". Este concepto tiene importancia para nuestro ordenamiento jurídico vigente, ya que cualquier norma o situación jurídica puede ser analizada a partir de este concepto. La Corte Constitucional lo reiteró en los siguientes términos:

12 Fabio Enrique Pulido, "Análisis de la interpretación y construcción del derecho a la vida en la jurisprudencia constitucional colombiana”, Díkaion 23, núm. 2 (diciembre 2014), http://dikaion.unisabana.edu.co/index. php/dikaion/article/view/4497/3898 (acceso marzo 20, 2017).

13 Por ejemplo: "Todo individuo tiene derecho a la vida [...]". Organización de Naciones Unidas [ONU], Declaración universal de los derechos humanos (París, 10 de diciembre de 1948), art. 3.

"El derecho a la vida es inherente a la persona humana. Este derecho estará protegido por la ley. Nadie podrá ser privado de la vida arbitrariamente". Organización de Naciones Unidas [ONU], Pacto internacional de derechos civiles y politicos (París, 16 de diciembre de 1966), art. 6, núm. 1.

" 1 . Toda persona tiene derecho a que se respete su vida. Este derecho estará protegido por la ley y, en general, a partir del momento de la concepción. Nadie puede ser privado de la vida arbitrariamente [...]". Organización de los Estados Americanos [OEA], Convención americana sobre derechos humanos (San José, 18 de julio de 1978), art. 4, núm. 1.

14 "La dirección general de la economía estará a cargo del Estado. Este intervendrá [...] con el fin de conseguir en el plano nacional y territorial, en un marco de sostenibilidad fiscal, el mejoramiento de la calidad de vida de los habitantes". República de Colombia, Constitución Politica, art. 334.

"El bienestar general y el mejoramiento de la calidad de vida de la población son finalidades sociales del Estado". República de Colombia, Constitución Política, art. 336. 
En reiterada jurisprudencia, esta Corporación ha sostenido que el derecho constitucional fundamental a la vida no significa la simple posibilidad de existir sin tener en cuenta las condiciones en que ello se haga, sino que, por el contrario, supone la garantía de una existencia digna, que implica para el individuo la mayor posibilidad de despliegue de sus facultades corporales y espirituales, de manera que cualquier circunstancia que impida el desarrollo normal de la persona, siendo evitable de alguna manera, compromete el derecho consagrado en el artículo 11 de la Constitución [...] (cursivas propias). ${ }^{15}$

Si bien no existe pronunciamiento expreso de la Corte Constitucional sobre la vida digna, es posible inferirla a partir de la definición de vida digna planteada líneas arriba: la indignidad se configura cuando se lleva una vida en condiciones insoportables o se atraviesa por un estado que no se está en el deber jurídico de soportar.

\subsection{Distanasia}

Al analizar la literatura de la Organización Mundial de la Salud se encuentra que no es posible identificar una definición puntual de distanasia dictada por ella. ${ }^{16}$

Ahora bien, en el ámbito nacional, el valor de la vida es tan significativo que incluso existe la posición de mantenerla aun cuando esta sea "indigna", lo que más allá de su reproche moral, es jurídicamente viable, pues no es sancionada por la legislación penal vigente. El salvamento de voto de la Sentencia C-239 de 1997 aclara que la distanasia consiste básicamente en "retrasar la muerte".

Explica la Corte Constitucional que la distanasia radica en hacer todo lo posible, por todos los medios, para obtener una "[...] prolongación artificial de la agonía de un moribundo [...]". ${ }^{17}$

El mismo Tribunal Constitucional retoma el concepto y lo define como "la prolongación de la vida por cualquier medio, incluso, causando efectos perversos en

Colombia, Corte Constitucional, Sentencia T-444 de 10 de junio de 1999 M. P. Eduardo Cifuentes.

16 Organización Mundial de la Salud [OMS], Más sano, más justo, más seguro. La travesía de la salud mundial 2007-2017 (Ginebra: Autor, 2017).

17 Colombia, Corte Constitucional, Sentencia C-239 de 20 de mayo de 1997, M. P. Carlos Gaviria. 
la salud, dignidad y vida del paciente. El objetivo de esta práctica consiste en impedir innecesariamente la muerte de la persona. [...] (cursivas propias). ${ }^{18}$

La distanasia podría catalogarse como el antónimo de la eutanasia, toda vez que supone un "ensañamiento" o una "obstinación terapéutica" para mantener la vida, sin importar el sufrimiento o las condiciones que reporte el paciente, ya que el fin último es la preservación.

\subsection{La terminación de la vida y sus modalidades}

La vida es una garantía, un bien y un derecho protegido por el Estado colombiano y por diversas disposiciones del orden internacional. Con todo, al Estado escapa la regulación de algunas formas de terminación de la vida, que suponen la anulación del individuo. De aquí surge el concepto de "suicidio" y otros términos como genocidio, eugenesia, homicidio, homicidio por piedad, eutanasia y suicidio asistido.

A continuación se presenta una breve síntesis sobre los términos que componen las categorías de terminación de la vida en Colombia. En los términos de este artículo de reflexión ${ }^{19}$ podemos afirmar que en nuestro país una persona puede perder la vida por una de cuatro situaciones: i) causas naturales (no implican decisiones de sujeto alguno); ii) decisión y ejecución propia; iii) decisión propia ejecutada por un tercero, y iv) decisión y ejecución de un tercero. Al ir de una categoría a otra se pasa de la inexistencia de sanciones jurídicas hasta su progresivo agravamiento.

\subsubsection{Terminación de la vida por causas naturales}

En la primera categoría hemos decidido ubicar a la muerte por causas naturales. ${ }^{20}$ La OMS estudia el fenómeno de la muerte desde una perspectiva estadística y de las patologías que ponen fin a la vida en todo el mundo. Analiza datos de mortalidad

Colombia, Corte Constitucional, Sentencia T-970 de 15 de diciembre de 2014, M. P. Luis Vargas.

19 Somos conscientes de que existen otras formas y métodos de terminación de la vida, algunos jurídicamente relevantes, como la pena de muerte o el aborto (aún se discute si se termina con la vida de un ser humano o de un prospecto de vida denominado nasciturus); sin embargo, estos temas merecen mayor profundidad y exponerlos en este texto escaparía a la delimitación conceptual precisada al inicio y, por ende, no serán mencionados.

20 Entendida como la causada por enfermedad, de acuerdo con el Instituto Nacional de Medicina Legal y Ciencias Forenses y la Clasificación internacional de enfermedades (CIE X) con fines epidemiológicos. Instituto Nacional de Medicina Legal y Ciencias Forenses, "Guía de procedimientos para la realización de necropsias medicolegales" http://www.medicinalegal.gov.co/documents/10180/2118293/gu\%C3\%ADa+para+la+realizaci\%7Bon+de+necropsias+m\%C3\%A9dico+legales+INMLCF.pdf/d99elde1-89c0-4a44-a5f9-39fdd4f8f70b (acceso abril 14, 2017). 
e indica el número de defunciones por lugar, intervalo y causa, sin diferenciar aquellos decesos suscitados por causas "naturales". Así lo expresa:

[...] los datos de mortalidad de la OMS reflejan las defunciones recogidas en los sistemas nacionales de registro civil, con las causas básicas de defunción codificadas por las autoridades nacionales.

La causa básica de defunción se define como "la enfermedad o lesión que desencadenó la sucesión de eventos patológicos que condujeron directamente a la muerte, o las circunstancias del accidente o acto de violencia que produjeron la lesión mortal", según lo expuesto en la Clasificación Internacional de Enfermedades [...] (cursivas propias). ${ }^{21}$

Como se ve, no existe un criterio único establecido por la OMS para definir la muerte por causas naturales, sino que se habla de las "causas básicas de defunción", término que, en nuestro sentir, agrupa la generalidad de circunstancias determinantes de la muerte, sin distinguir entre aquellas que son "naturales" y aquellas provocadas.

Para efectos de este análisis se podría concluir que la muerte por causas naturales consiste en el fallecimiento generado por una enfermedad ${ }^{22}$ o por hechos de la naturaleza, por ejemplo, la fuerza mayor. ${ }^{23}$ Sobre este punto no existe sanción jurídica.

21 Organización Mundial de la Salud [OMS], "Mortalidad", http://www.who.int/topics/mortality/es/ (acceso noviembre 11, 2017).

22 El alcance de este artículo impide examinar todo el fenómeno del autocuidado y su relación con el desarrollo de enfermedades mortales, como el caso de quienes tienen hábitos de vida perjudiciales para su salud, lo que plantearía una objeción para el carácter "involuntario" de las enfermedades.

23 Sobre el particular, al analizar los conceptos de caso fortuito y fuerza mayor, el Consejo de Estado en Sala de consulta y servicio civil refirió que, a diferencia de la asimilación que históricamente hace la Corte Suprema de Justicia entre ambos conceptos, la jurisprudencia contencioso administrativa distingue estas dos figuras y define el caso fortuito como el suceso interno en el campo de actividad de quien produce el daño, mientras la fuerza mayor consiste en un acontecimiento externo a la actividad de quien produce el daño; señala, en términos generales, que la irresistibilidad es el criterio fundamental determinante de la fuerza mayor y que la imprevisibilidad lo es del caso fortuito (Consulta No. N1792, 2006). En esos términos, la fuerza mayor consistiría en un hecho de la naturaleza cuyo advenimiento ponga fin a la vida del individuo. 


\subsubsection{Terminación de la vida por decisión y ejecución propia}

En palabras de la OMS, el suicidio 24 "es un grave problema de salud pública [...] muchos suicidios se producen impulsivamente en momentos de crisis que menoscaban la capacidad para afrontar las tensiones de la vida" (cursivas propias). ${ }^{25}$

La OMS llama la atención al mencionar: "En la actualidad, unos pocos países han incluido la prevención del suicidio entre sus prioridades sanitarias, y solo 28 países han notificado que cuentan con una estrategia nacional de prevención del suicidio" (cursivas propias). ${ }^{26}$

En contraste con anteriores fenómenos indefinidos por la OMS, el suicidio ha sido objeto de importantes informes por parte de la organización internacional. ${ }^{27}$ Es claro que en el concepto analizado — terminación de la vida por decisión y ejecución propias - se encuadra exclusivamente la figura del suicidio, pues el acto depende solo de la reflexión personal del individuo que provoca su propia muerte; por ello, tanto la decisión como la ejecución no traspasan la órbita íntima del ser humano.

El término que ahora nos ocupa tiene diversas acepciones según el autor que se estudie; sin embargo, para el objeto de esta investigación hemos decidido tomar en consideración la desarrollada por Emile Durkheim, ${ }^{28}$ quien lo describió como

24 Se reitera que la OMS fija su atención en las estadísticas para cuantificar los fenómenos de salud en el mundo. Estima que cerca de 800.000 personas se suicidan cada año, lo que se traduce en una muerte cada 40 segundos y destaca también que por cada suicidio hay muchas más tentativas cada año. Asimismo, ubica al suicidio como la segunda causa de defunción en el grupo de 15 a 29 años. El acto se consuma por medio de la ingesta de plaguicidas, el ahorcamiento y por disparo de armas de fuego. Organización Mundial de la Salud [OMS], "Suicidio", http://www.who.int/mediacentre/factsheets/ss398/es/ (acceso noviembre 29, 2017).

25 OMS, "Suicidio".

26 OMS, "Suicidio".

Se muestra que la tendencia actual está encaminada a tratar el suicidio como un problema de salud pública más que una conducta punible, lo que demuestra la progresividad de las sociedades en los últimos tiempos; sin embargo, aún es mínimo el número de países que consagran tratamientos de prevención, pues persisten el estigma y tabú sobre el tema.

27 Se destaca el primer informe mundial sobre el suicidio, denominado Prevención del suicidio: un imperativo global, publicado en 2014, que propende por el aumento de la sensibilización y señala que el suicidio es una "[...] alta prioridad en la agenda mundial de salud pública [...]". OMS, "Suicidio". También se resalta que los Estados miembros se comprometieron a trabajar para alcanzar la meta mundial de reducir las tasas nacionales de suicidios en un 10 \% para 2020. Organización Mundial de la Salud, Plan de acción sobre salud mental 2013-2020 (Ginebra: Organización Mundial de la Salud, 2013).

28 Durkheim describe tres tipologías de suicidio; el egoísta (ejecutado cuando se piensa esencialmente en sí mismo), el altruista (por imperativos sociales se obedecen las órdenes del grupo hasta el extremo de ahogar en sí mismo el instinto de conservación) y el anómico (caracterizado por un estado de irritación y de disgusto). Para su análisis emplea técnicas estadísticas que le permiten establecer diferencias, entre el 
"todo caso de muerte que resulta directa o indirectamente de un acto positivo o negativo realizado por la víctima misma, y que, según ella sabía, debía producir este resultado" (cursivas propias). ${ }^{29}$ Esta definición describe de manera más apropiada el fenómeno analizado, pues en ella es claro el factor volitivo que media en este acto, como lo consagra también uno de los diccionarios de la Real Academia Española "[...] acto voluntario por el que una persona pone fin a su existencia". ${ }^{30}$

Por tanto, es apenas obvio que este fenómeno escape a la regulación estatal y por ello no es razonable establecer una sanción jurídica para ese supuesto de hecho; empero, no siempre fue así. De hecho, el suicidio ha sido tratado de diversas formas según el tipo de sociedad, civilización y espacio temporal donde ocurriera. Basta con señalar que, en la Edad Media, ante la ocurrencia de un suicidio se juzgaba al cadáver. ${ }^{31}$ Asimismo, "durante largos años, fue común castigar al sobreviviente o al cadáver, y poco importaba la forma o el motivo que daban lugar al intento". 32

Superado ese estadio previo a la Modernidad, es posible decir que en Colombia no existe una norma legal que prohíba, sancione o reproche el acto suicida en su forma pura y simple, por lo que existe disponibilidad absoluta del derecho a la vida propia por parte de su titular y escapa de las manos del Estado su protección o regulación.

\subsubsection{Terminación de la vida por decisión propia ejecutada por un tercero}

Esta categoría constituye uno de los aspectos centrales de este escrito, ya que abarca las figuras de eutanasia, suicidio asistido y homicidio por piedad, caracterizadas por la decisión personal de terminar con la vida propia por parte del sujeto pasivo de la figura (al menos, en apariencia o prima facie) y la ejecución material del acto

número de suicidios existentes en poblaciones humanas determinadas. Émile Durkheim, El suicidio: estudio de sociología (Buenos Aires: Losada, 1897).

29 Durkheim, El suicidio, 5.

30 Real Academia Española, "Suicidio" en Diccionario del español jurídico, http://dej.rae.es/\#/entry-id/E228300 (acceso marzo 19, 2017).

31 Durante la Edad Media y el Renacimiento existieron penalidades religiosas contra el suicidio y los suicidas. Muchas de esas "sanciones" consistían en no ser enterrados, ser difamados y humillados en público (aun después de muertos). Sin embargo, en algunas civilizaciones no solo fue juzgado moralmente, sino que también se le declaró un crimen y era sancionado penalmente. Para profundizar sobre este tema, Dora Salman Rocha, "Futuro imperfecto: dimensión hermenéutico-simbólica del suicidio en la obra de Jorge Semprún" (tesis para obtener el grado de doctora en Letras Modernas, Universidad Iberoamericana, 2011), 9-60.

32 Salman Rocha, "Futuro imperfecto: dimensión hermenéutico-simbólica del suicidio", 16. 
que produce la muerte por parte de un tercero, sujeto activo de la conducta. A continuación se describen a grandes rasgos las características de las figuras enunciadas.

\section{- Eutanasia}

Este término supone una respuesta a una proposición lógica de difícil resolución, ya que, por regla general, la mayoría de personas desea estar viva; muy pocos ansían morir. Un grupo aún más reducido está habilitado jurídica y moralmente para solicitar la aplicación de la eutanasia y de él son pocos a los que se les aplica este procedimiento, puesto que el camino presenta innumerables limitaciones.

Para la Associació Catalana d'Estudis Bioétics (ACEB), que cita a la OMS, la eutanasia es la "acción del médico que provoca deliberadamente la muerte del paciente", 33 lo anterior desde el punto de vista médico.

Para Ana Isabel Gómez, "[...] la eutanasia como concepto jurídico debe ser entendida desde sus antecedentes en Colombia [... ]" ${ }^{34}$ La doctora manifiesta que el primer antecedente de relevancia para este tema en el país es la Sentencia C 239 de 1997, ${ }^{35}$ de la Corte Constitucional. En ella se plantea que cuando una persona mayor de 18 años, ${ }^{36}$ en pleno uso de sus facultades mentales, está aquejada por una enfermedad de carácter terminal y, a pesar de las medidas de cuidado, considera, desde sus valores morales, creencias religiosas y principios, que el sufrimiento al que está siendo sometida es insoportable e indigno, puede ante la solicitud reiterada e informada pedir a su médico ayudarle a acceder a la figura de la eutanasia para así terminar con su vida.

33 Associació Catalana d'Estudis Bioétics, "Razones del 'no' a la Eutanasia” http://www.bioeticacs.org/iceb/ seleccion_temas/eutanasia/Razones_del_no_a_la_eutanasia.pdf (acceso junio 4, 2018).

34 "Doctora médico pediatra Universidad del Rosario Ana Isabel Gómez Córdoba", Video de YouTube, 2:55, publicado por "YouTube", 27 de julio de 2015, https://www.youtube.com/watch?v=qGKcQUITLAw (acceso octubre 15, 2016).

35 Como ya se dijo, en ese análisis de constitucionalidad, la Corte desarrolla múltiples figuras que son descritas en este artículo, en particular la eutanasia y las diversas modalidades de muerte en Colombia.

36 No obstante, la condición de edad ha sido revaluada en la reciente sentencia T-544/17. La Corte estudió una tutela presentada por los padres de un menor en contra de Salud EPS, con el fin de garantizar la muerte digna de su hijo. Los padres del menor solicitaron a la EPS la práctica de la eutanasia, pero la entidad no contestó, pese a que existía un fallo de tutela que ordenaba el procedimiento. El menor murió. No obstante, la Corte Constitucional ordenó al Ministerio de Salud en un plazo de un año que presentara un proyecto de ley ante el Congreso para regular el derecho fundamental de niños y adultos a morir dignamente. Colombia, Corte Constitucional, Sentencia T-544 de 25 de agosto de 2017, M. P. Gloria Ortiz. 
También fue en esta Sentencia que se exhortó por primera vez al Congreso de la República para que regulara la materia; no obstante, por más de veinte años se ha mantenido un vacío legislativo sobre el tema en el país, salvo la regulación del Ministerio de Salud. ${ }^{37}$

El segundo antecedente jurídico y jurisprudencial más importante, de acuerdo con Gómez, es la Sentencia T-970 de 2014 de la Corte Constitucional, en la que se explican los conceptos de eutanasia, distanasia y homicidio por piedad. Además, se habla del derecho a morir dignamente como creación jurisprudencial. En esta Sentencia se ordena al Ministerio de Salud:

[...] emitir una directriz a todos los prestadores del servicio de salud, para que conformen un grupo de expertos interdisciplinarios que cumplirán varias funciones cuando se esté en presencia de casos en los que se solicite el derecho a morir dignamente $[\ldots]^{38}$

Por otra parte, se insta al Ministerio de Salud para que cree un protocolo que verifique la seguridad legal y la existencia de las condiciones fijadas en la primera Sentencia (C 239/97) que permitan dar una terminación anticipada de la vida. De todo lo anterior concluye Gómez que el concepto de eutanasia ha sido resultado de estas dos Sentencias.

Para esta reflexión se retomará el concepto expuesto por la Corte Constitucional en la segunda sentencia hito, esto es, la Sentencia T-970 de 2014, toda vez que aclara que no existe unidad de criterio frente al tema de la eutanasia, pero sí unas circunstancias en las que su aplicación es viable:

Las definiciones sobre eutanasia son múltiples y actualmente no se cuenta con alguna totalmente aceptada. No obstante, lo que sí está claro es que en este procedimiento deben concurrir los siguientes elementos: (i) el sujeto pasivo que padece una enfermedad terminal; (ii) el sujeto activo que realiza la acción u omisión tendiente a acabar con los dolores del paciente quien, en todos los casos, debe ser un médico; (iii) debe producirse por petición expresa, reiterada

37 Resolución 1216 del 20 de abril de 2015, del Ministerio de Salud y Protección Social, por medio de la cual se cumple la orden cuarta de la Sentencia T-970 de 2014 de la Corte Constitucional en relación con las directrices para la organización y el funcionamiento de los comités para hacer efectivo el derecho a morir con dignidad.

38 Colombia, Corte Constitucional, Sentencia T-970 de 15 de diciembre de 2014. 
e informada de los pacientes. Así, [... . cuando se verifican en su totalidad, la eutanasia puede provocarse [...] (cursivas propias). ${ }^{39}$

También es importante retomar la primera sentencia hito (SC 239/97), pues de su salvamento de voto se infiere que no existe una sola clase de eutanasia, sino que es posible clasificarla en activa y pasiva, a saber:

i) Eutanasia activa: se considera que esta actividad está dirigida a causar la muerte.

ii) Eutanasia pasiva: es la negativa o por omisión. En este caso la muerte es causada por no prestar los medios necesarios para mantener la vida. ${ }^{40}$

Tras aclarar lo anterior, esto es, las sentencias que sirven de base para este escrito, se establecerá la diferencia con otros términos asociados muchas veces de manera errónea con la eutanasia.

\section{- Suicidio asistido}

El concepto más relevante de esta figura lo encontramos en una de las sentencias que ha sido referencia constante en este escrito, esto es, la Sentencia T-970 de 2014, en la que la Corte constitucional define las características básicas de esta figura:

En este evento, el sujeto activo y pasivo se confunde pues la intervención del médico no es directa, ya que es el mismo enfermo quien provoca su muerte. Ese es el caso en el que galeno proporciona todos los medios necesarios para que el enfermo termine por sí mismo con su vida. En otras palabras, simplemente ayuda al suicida a cometer la conducta [...] (cursivas propias). ${ }^{41}$

Esta figura se limita al suministro de los medios necesarios para morir por parte del médico al enfermo, para que este último ejecute el acto por sí mismo. ${ }^{42}$ Este mecanismo de muerte se diferencia de otros porque el médico, a pesar de tener gran influencia sobre la situación, no opera directamente y en consecuencia la

Colombia, Corte Constitucional, Sentencia T-970 de 15 de diciembre de 2014.

Colombia, Corte Constitucional, Sentencia C-239 de 20 de mayo de 1997.

Colombia, Corte Constitucional, Sentencia T-970 de 15 de diciembre de 2014.

42 Lo que en apariencia excluiría este fenómeno de la categoría terminación de la vida por decisión propia ejecutada por un tercero; sin embargo, los sujetos de la conducta en ocasiones se confunden y, por ello, se ha fijado dentro de esta categoría, por la especial relevancia de quien suministra los medios para ejecutar el acto de muerte. 
conducta es ejecutada por el paciente. Esta modalidad se encuentra penalizada por el Artículo 107 del Código Penal colombiano y constituye una forma autónoma de muerte que no debe equipararse a otras figuras.

\section{- Homicidio por piedad ${ }^{43}$}

Para definirlo es preciso traer a colación el concepto desarrollado por la Corte Constitucional:

[... la la acción de quien obra por la motivación especifica de poner fin a los intensos sufrimientos de otro [...] un tipo que precisa de unas condiciones objetivas en el sujeto pasivo, consistentes en que se encuentre padeciendo intensos sufrimientos, provenientes de lesión corporal o de enfermedad grave o incurable, es decir, [...] se trata de eliminar [...] de hacer que cese el dolor del que padece sin ninguna esperanza de que termine su sufrimiento [... (cursivas propias). ${ }^{44}$

Esta clase de homicidio tiene por condición especial "la piedad", situación definida por la Corte como "un estado afectivo de conmoción y alteración anímica profundas, [...] mueve a obrar en favor de otro y no en consideración a sí mismo [...]". 45

Respecto al tratamiento jurídico penal en el ordenamiento colombiano encontramos que esta conducta está sancionada por el Artículo 106 del Código Penal colombiano. Empero, la Corte Constitucional ha considerado:

Quien mata a otro por piedad, con el propósito de ponerles fin a los intensos sufrimientos que padece, obra con un claro sentido altruista, y es esa motivación la que ha llevado al legislador a crear un tipo autónomo, al cual atribuye una pena considerablemente menor a la prevista para el delito de homicidio simple o agravado. Tal decisión no desconoce el derecho fundamental a la vida, pues la conducta, no obstante, la motivación, sigue siendo antijurídica, es decir, legalmente injusta (cursivas propias). ${ }^{46}$

\footnotetext{
43 También denominado homicidio pietístico por la Corte Constitucional en reiterada jurisprudencia.

44 Colombia, Corte Constitucional, Sentencia C-239 de 20 de mayo de 1997.

45 Colombia, Corte Constitucional, Sentencia C-239 de 20 de mayo de 1997.

46 Colombia, Corte Constitucional, Sentencia C-239 de 20 de mayo de 1997.
} 


\section{- Diferencia entre eutanasia, suicidio asistido y homicidio por piedad}

Para finiquitar este aparte se ofrece una clara diferenciación entre los tres términos que son asimilados erróneamente.

En la eutanasia, el médico es quien directamente (inmediatez) ejecuta el procedimiento que conduce a la muerte del paciente, con el entendido de que ha mediado una solicitud reiterada, expresa e informada del paciente. Por otra parte, la práctica de la eutanasia exige el estricto cumplimiento de ciertas circunstancias o condiciones que determinan la viabilidad del procedimiento.

Por su parte, en el suicidio asistido, ante la solicitud del paciente, el médico facilita los medios para que sea él mismo quien termine con su vida, sin la intervención directa (mediato).

En contraste, el homicidio por piedad supone que un particular, ${ }^{47}$ termine con la vida de otra persona por "piedad [...] para poner fin a intensos sufrimientos provenientes de lesión corporal o enfermedad grave e incurable [...]", ${ }^{48}$ como se explicó líneas arriba. Se trata de una conducta punible tipificada en el Artículo 106 del Código Penal; sin embargo, la Corte Constitucional precisó el tratamiento particular de este acto:

[... la la actuación del sujeto activo carece de antijuridicidad, porque se trata de un acto solidario, que no se realiza por la decisión personal de suprimir una vida, sino por la solicitud del "enfermo" que pide que le ayuden a morir [....$^{49}$

La eutanasia y el suicidio asistido tienen en común la intervención de profesionales de la medicina. Por su parte, la eutanasia comparte con el homicidio por piedad la falta de participación del enfermo. El punto de convergencia de todas ellas es el consentimiento del sujeto pasivo, que debe ser libre, expreso, espontáneo, informado y manifestado inequívocamente..$^{50}$

No obstante, la Corte ha establecido que debe ser un médico, único profesional calificado.

48 Colombia, Corte Constitucional, Sentencia C-239 de 20 de mayo de 1997.

-9 Colombia, Corte Constitucional, Sentencia C-239 de 20 de mayo de 1997.

50 De lo analizado en las jurisprudencias de referencia, se infiere que el consentimiento implica que la persona posea información seria y fiable acerca de su enfermedad, de las opciones terapéuticas y de su pronóstico y cuenta con la capacidad intelectual suficiente para tomar la decisión. 


\subsubsection{Terminación de la vida por decisión y ejecución de un tercero}

La última categoría corresponde a la decisión de un tercero sobre la vida de un individuo; la terminación de la vida en estos casos es consecuencia de la disposición y ejecución egoísta del acto de muerte. Hemos agrupado aquí las conductas de homicidio, eugenesia y genocidio, cada una de ellas reprochables y sancionadas tanto por el ordenamiento jurídico nacional como por el ordenamiento internacional.

\section{- Homicidio}

La figura del homicidio ha estado presente a lo largo de la historia de la humanidad y ha sido sancionada en todos los tiempos en cada una de las sociedades. En Colombia es penalizada por el ordenamiento jurídico, ${ }^{51}$ dado que la muerte, en este caso, es "el producto del sentimiento egoísta del victimario, que anula una existencia, porque a su juicio no tiene ningún valor". ${ }^{52}$

El homicidio es una de las conductas más graves en contra del ser humano y por ello su penalización es apenas lógica, pues corresponde a la sanción por la negación de la vida del otro.

Visto lo anterior, queda claro que en el homicidio no existe posibilidad de disponer del derecho a la vida propia.

\section{- Eugenesia}

La Sentencia C-239 de 1997 permite entender el concepto de eugenesia u homicidio eugenésico.

La Corte Constitucional ha precisado que dicha figura se caracteriza porque "persigue como fin, con fundamento en hipótesis seudocientíficas, la preservación y el mejoramiento de la raza o de la especie humana [...]" (cursivas propias). ${ }^{53}$

51 Colombia, Congreso de la República, Ley 599 de 2000, "Por la cual se expide el Código Penal" (Bogotá: Diario Oficial No. 44.097, 24 de julio de 2000), art. 103.

52 Colombia, Corte Constitucional, Sentencia C-239 de 20 de mayo de 1997.

53 Colombia, Corte Constitucional, Sentencia C-239 de 20 de mayo de 1997. 
Por otra parte, el Instituto Hispanoamericano de Suicidología define este término como "higiene racial', libera a la sociedad de los enfermos que son una carga". ${ }^{54}$

Así, la práctica eugenésica constituye una flagrante violación del derecho a la vida que, si bien no está expresamente prohibida por la legislación penal colombiana, se entiende proscrita por razones de humanidad e incluso podría relacionarse con la figura del genocidio que se pasa a analizar. Con todo, esta figura excluye cualquier tipo de disponibilidad de la vida propia.

\section{- Genocidio}

Esta conducta se encuentra proscrita no solo por el ordenamiento jurídico de Colombia, ${ }^{55}$ sino por innumerables normas de derecho internacional ${ }^{56}$ (delito de derecho internacional). La Corte Constitucional ha revisado esta figura en diversa jurisprudencia; no obstante, el concepto puntual que sirve a este estudio es el desarrollado en la Sentencia C-177 de 2001, que establece:

[...] consiste en la destrucción sistemática y deliberada de un grupo humano, que tenga una identidad definida [...]. La incriminación de la conducta sistemática de aniquilación de un grupo [...] encuentra pleno respaldo en los valores y principios que informan la Constitución Política de 1991 entre los que se cuentan la convivencia, la paz y el respeto irrestricto a la vida y a la existencia de los grupos humanos, considerados como tales, con independencia de su etnia, nacionalidad, credos políticos, filosóficos o religiosos (cursivas propias). ${ }^{57}$

54 Alejandro Águila, "Eutanasia y Suicidio... quién decide", http://www.suicidologia.com.mx/wp-content/ uploads/2017/01/Eutanasiaysuicidio.pdf (acceso marzo 14, 2017).

55 Colombia, Congreso de la República, Ley 599 de 2000, art. 101

56 Por ejemplo, la Convención para la prevención y la sanción del delito de genocidio en la totalidad de su articulado, en especial: "Las Partes contratantes confirman que el genocidio, ya sea cometido en tiempo de paz o en tiempo de guerra, es un delito de derecho internacional que ellas se comprometen a prevenir y a sancionar [...]". Organización de las Naciones Unidas [ONU], Convención para la prevención y la sanción del delito de genocidio (Washington, 9 de diciembre de 1948), art. 1.

Y el Estatuto de Roma: "1. La competencia de la Corte se limitará a los crímenes más graves de trascendencia para la comunidad internacional en su conjunto. La Corte tendrá competencia [...] respecto de los siguientes crímenes: a) El crimen de genocidio [...]. Artículo 6. [...] A los efectos del presente Estatuto, se entenderá por 'genocidio' cualquiera de los actos [...] perpetrados con la intención de destruir total o parcialmente a un grupo nacional, étnico, racial o religioso [...]". Organización de las Naciones Unidas [ONU], Estatuto de Roma de la Corte Penal Internacional (Roma, 17 de julio de 1998), art. 5, num. 1, lit. a y art. 6.

57 Colombia, Corte Constitucional. Sentencia C-177 de 14 de febrero de 2001, M. P. Fabio Morón. 
No se puede predicar la disponibilidad del derecho a la vida propia en términos de genocidio, máxime cuando, como ya se dijo, la legislación interna lo sanciona penalmente de manera expresa e incluso prohíbe su promoción..$^{58}$

Después de analizadas las modalidades subyacentes al derecho a la vida en Colombia, es posible sintetizar la información expuesta en la Tabla 1.

Tabla 1. Modalidades de terminación de la vida y su regulación en Colombia

\begin{tabular}{|l|l|}
\hline \multicolumn{1}{|c|}{ Término } & \multicolumn{1}{c|}{ Regulación en Colombia } \\
\hline Genocidio & $\begin{array}{l}\text { Prohibición expresa de comisión (art. 101 CP) y de apología (art. } 102 \\
\text { CP) Conlleva sanción. }\end{array}$ \\
\hline Eugenesia & Prohibición tácita. En conexidad con el genocidio. Conlleva sanción. \\
\hline Homicidio & Prohibición expresa (art. 103 CP). Conlleva sanción. \\
\hline $\begin{array}{l}\text { Homicidio por } \\
\text { piedad }\end{array}$ & Prohibición expresa (art. 106 CP). Conlleva sanción. \\
\hline Suicidio asistido & Prohibición expresa (art. 107 CP). Conlleva sanción. \\
\hline Eutanasia & $\begin{array}{l}\text { Permitida bajo estrictas circunstancias. } \\
\text { Resolución 1216 de 2015 del Ministerio de Salud y Protección social. } \\
\text { Sentencias de la Corte Constitucional. }\end{array}$ \\
\hline Suicidio & Permitido en Colombia. \\
\hline
\end{tabular}

Fuente: elaboración propia

58 Colombia, Congreso de la República, Ley 599 de 2000, art. 102. 


\section{Conclusiones}

Respecto al derecho a la vida, se resumen las ideas expuestas en la Figura 1.

Figura 1. Facetas de la vida en Colombia

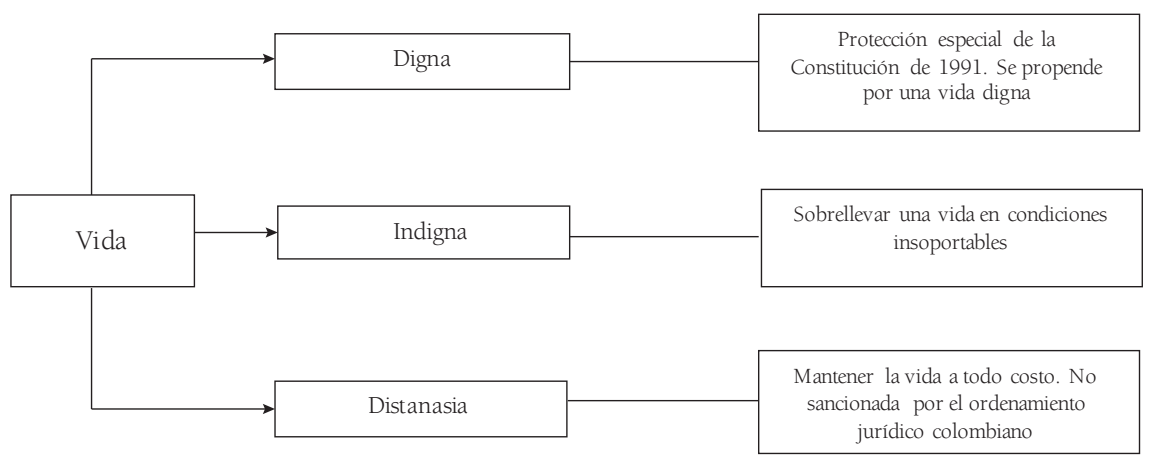

Fuente: elaboración propia

Las modalidades de vulneración del derecho a la vida se exponen en la Figura 2.

Figura 2. Clasificación de las modalidades de terminación de la vida en Colombia

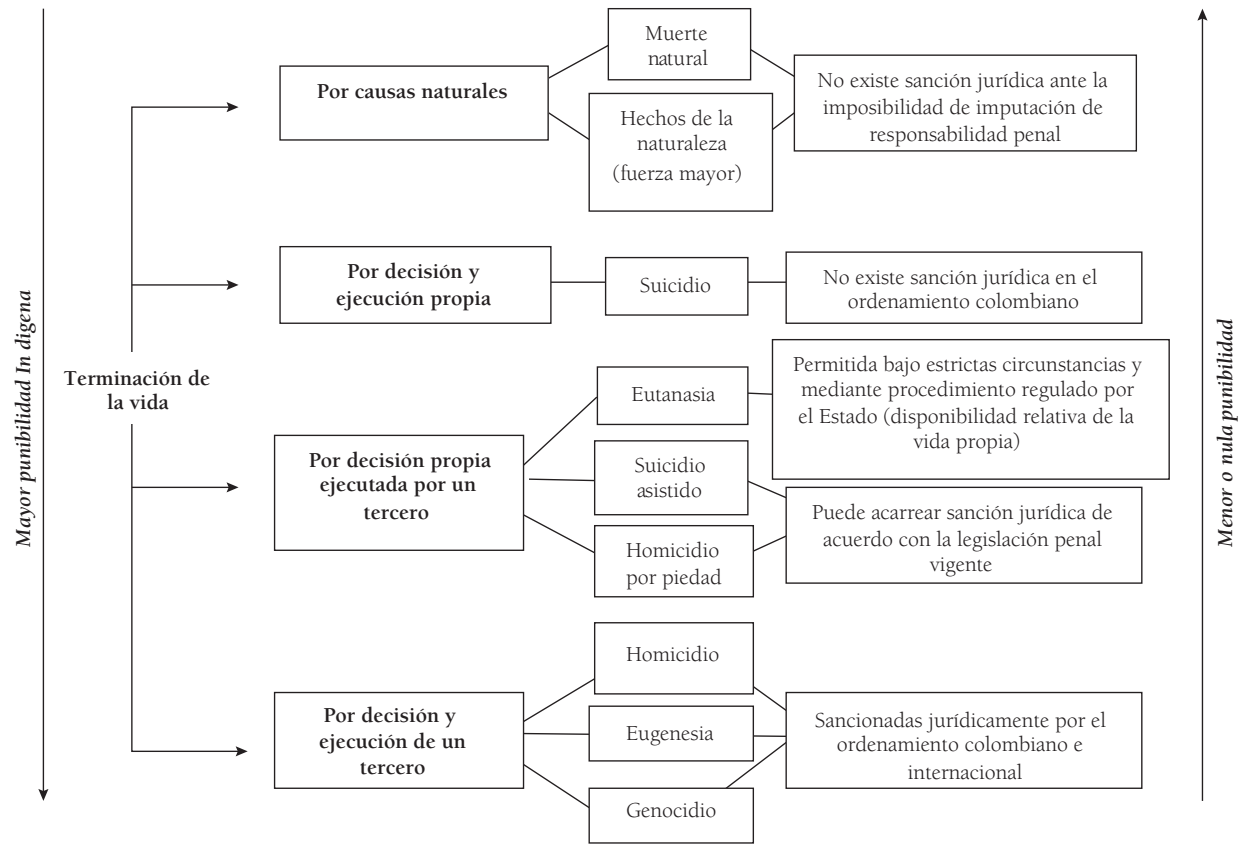

Fuente: elaboración propia 
La tesis de la disponibilidad relativa de la vida propia en Colombia encuentra asidero en innumerable jurisprudencia de la Corte Constitucional, que de manera tácita ha considerado esta posibilidad por la vía de la eutanasia. Por lo anterior, es posible hablar de una facultad jurídica intrínseca en el derecho a la vida que permite a los individuos terminar con su propia existencia, siempre que se esté dentro de los presupuestos estatales, pues se trata de una disponibilidad relativa y no absoluta.

En contraste, solo desde la figura del suicidio (como fue estudiada) se encuentra que la disponibilidad del derecho a la vida propia es absoluta, por cuanto es un fenómeno social que escapa al ius puniendi del Estado colombiano y, por lo tanto, no puede ser sancionado.

Por otra parte, el derecho a morir dignamente encuentra su soporte en el principio de dignidad humana, el libre desarrollo de la personalidad y la autonomía del individuo, que es plenamente libre de tomar decisiones personalísimas que, en principio, no deberían interesar al Estado.

\section{Referencias}

Águila, Alejandro. "Eutanasia y suicidio... Quién decide". http://www.suicidologia.com. $\mathrm{mx} / \mathrm{wp}$-content/uploads/2017/01/Eutanasiaysuicidio.pdf (acceso marzo 14, 2017).

Associació Catalana d'Estudis Bioétics. "Razones del 'no' a la eutanasia". http://www. bioeticacs.org/iceb/seleccion_temas/eutanasia/Razones_del_no_a_la_eutanasia.pdf (acceso mayo 15, 2018).

Canadian Medical Association. "Physician-assisted death". Canadian Medical Association Journal 152, núm. 2 (1995): 248A-248B.

Canadian Medical Association. Euthanasia and Assisted Suicide (update 2007). Ottawa: AMC/ CMA, 2007.

Carrió, Genaro. "Introducción" en Cómo hacer cósas con palabras, compilado por James Urmson, 7-15. Buenos Aires: Paidós, 1971.

Colombia, Congreso de la República. Ley 57 de 1887, "Por la cual se expide el Código Civil". Bogotá: Diario Oficial No. 2.867, 31 de mayo de 1873.

Colombia, Corte Constitucional. Sentencia C-239 de 20 de mayo de 1997. M. P. Carlos Gaviria. Colombia, Corte Constitucional. Sentencia T-444 de 10 de junio de 1999. M. P. Eduardo Cifuentes.

Colombia, Congreso de la República. Ley 599 de 2000, "Por la cual se expide el Código Penal". Bogotá: Diario Oficial 44.097, 24 de julio de 2000.

Colombia. Corte Constitucional. Sentencia C-177 de 14 de febrero de 2001. M. P. Fabio Morón. 
Colombia, Corte Constitucional. Sentencia T-408 de 4 de julio de 2013. M. P. Jorge Pretelt. Colombia, Corte Constitucional. Sentencia T-970 de 15 de diciembre de 2014. M. P. Luis Vargas. Colombia, Corte Constitucional. Sentencia T-544 de 25 de agosto de 2017. M. P. Gloria Ortiz. Durkheim, Émile. El suicidio: estudio de sociología. Buenos Aires: Losada, 1897.

"Doctora médico pediatra Universidad del Rosario Ana Isabel Gómez Córdoba". Video de YouTube. 2:55. Publicado por "YouTube". 27 de julio de 2015. https://www.youtube. com/watch?v=qGKcQUITLAw (acceso octubre 15, 2016).

Instituto Nacional de Medicina Legal y Ciencias Forenses. "Guía de procedimientos para la realización de necropsias medicolegales". http://www.medicinalegal.gov.co/ documents/10180/2118293/gu\%C3\%ADa+para+la+realizaci\%7Bon+de+necropsia s+m\%C3\%A9dico+legales+INMLCF.pdf/d99elde1-89c0-4a44-a5f9-39fdd4f8f70b (acceso abril 14, 2017).

Organización de Naciones Unidas [ONU]. Declaración universal de los derechos humanos. París, 10 de diciembre de 1948.

Organización de Naciones Unidas [ONU]. Pacto internacional de derechos civiles y políticos. París, 16 de diciembre de 1966.

Organización de las Naciones Unidas [ONU]. Estatuto de Roma de la Corte Penal Internacional. Roma, 17 de julio de 1998.

Organización de las Naciones Unidas [ONU]. "Prevención y la sanción del delito de genocidio". https://www.icrc.org/spa/resources/documents/misc/treaty-1948-convgenocide-5tdm6h.htm (acceso agosto 17, 2017).

Organización de los Estados Americanos [OEA]. Convención americana sobre derechos humanos. San José, 18 de julio de 1978.

Organización Mundial de la Salud [OMS]. Plan de acción sobre salud mental 2013-2020. Ginebra: Autor, 2013.

Organización Mundial de la Salud [OMS]. Más sano, más justo, más seguro. La travesía de la salud mundial 2007-2017. Ginebra: Autor, 2017.

Organización Mundial de la Salud [OMS]. "Mortalidad". http://www.who.int/topics/ mortality/es/ (acceso noviembre 11, 2017).

Organización Mundial de la Salud [OMS]. "Suicidio". http://www.who.int/mediacentre/ factsheets/fs398/es/ (acceso noviembre 29, 2017).

Parra Ávila, Elliot. "Análisis sobre las obligaciones". Pensamiento Jurídico 16, núm. 16 (2006): 113-121. https://revistas.unal.edu.co/index.php/peju/article/view/40372/ pdf_519 (acceso junio 6, 2018).

Parreiras, Mariana, Guilherme Cafure, Livia Pacelli, Lucas Silva, Sarah Rückl y Ângelo, Vera. "Eutanasia y suicidio asistido en países occidentales: una revisión sistemática". Bioética 24, núm 2 (2016): 355-367. 
Pulido, Fabio Enrique. "Análisis de la interpretación y construcción del derecho a la vida en la jurisprudencia constitucional colombiana”. Díkaion 23, núm. 2 (2014): 277-298. http://dikaion.unisabana.edu.co/index.php/dikaion/article/view/4497/3898 (acceso marzo 20, 2017).

Real Academia Española. "Suicidio" en Diccionario del español jurídico. http://dej.rae.es/\#/ entry-id/E228300 (acceso marzo 19, 2017).

República de Colombia. Constitución Política. Bogotá: Legis, 1991.

Salman Rocha, Dora. "Futuro imperfecto: dimensión hermenéutico-simbólica del suicidio en la obra de Jorge Semprún”. Tesis de doctorado, Universidad Iberoamericana, 2011. 